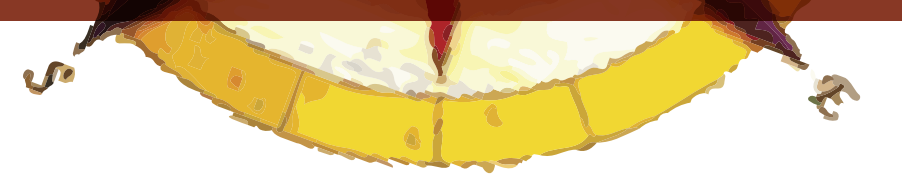

\title{
A EXTENSAO UNIVERSITÀRIA NA FORMAÇÃO DE PROFESSORES E ALUNOS PARA O ENSINO DE GEOGRAFIA.
}

\author{
Glória da Anunciação Alves ${ }^{1}$
}

\section{RESUMO}

A Semana de Geografia é um projeto de extensão universitária que visa articular o conhecimento produzido na Universidade com o criado nas escolas públicas do ensino básico. Ele se realiza nos dois espaços, Universidade e Escola pública, e os articula a partir da ida dos monitores (estudantes do curso de Geografia) às escolas participantes e com a vinda dos alunos dessas escolas à Universidade, para apresentação, debates , trocas tendo como ponto de partida o conhecimento geográfico. Além disso, propicia aos alunos do ensino básico conhecer, mesmo que superficialmente, a Universidade de São Paulo a partir de sua apresentação e conhecimento de sua função e seus espaços (museus, unidades didáticas, o restaurante universitário, ou seja, o campus no geral). Discutiremos aqui a importância da extensão universitária na formação/formação permanente de professores de Geografia e alunos no atual contexto social e econômico do neoliberalismo.

Palavras chaves: ensino de Geografia, extensão universitária, escola pública.

\section{RESUMEN}

La Semana de la Geografía es un proyecto de extensión universitaria que tiene como objetivo articular el conocimiento que se produce con la Universidad creado en las escuelas primarias públicas. Él realiza en ambos espacios, la universidad y la escuela pública, y se articula a partir de la forma en que los monitores (alumnos de Geografía ) a las escuelas participantes y con la llegada de los alumnos de estas escuelas a la Universidad, para su presentación, los debates , los intercambios que tienen como punto de los conocimientos geográficos de partida. Además, proporciona a los estudiantes de educación básica para conocer, aunque sea superficialmente, la Universidad de São Paulo a partir de su presentación y conocimiento de su función y de sus espacios (museos, las unidades docentes, el restaurante de la universidad, o en el campus, en general, ). Aquí hablamos de la importancia de la extensión universitaria en la formación / educación continua para los profesores 
y estudiantes de la geografía en el contexto social y económico actual del neoliberalismo.

Palabras clave: Geografía de enseñanza, extensión universitaria, la escuela pública.

\begin{abstract}
The Geography Week is a university extension project that aims to articulate the knowledge produced in the University with the one created in public primary schools. It is performed in both spaces, University and public school, and it is articulated by the monitors (Geography students) going to participating schools and with the coming of these schools students to the University, for presentation, debates, exchanges having as starting point the Geographical knowledge. It also provides the basic education students to know, even superficially, the University of Sao Paulo from its presentation and knowledge of its function and spaces (museums, teaching units, the university restaurant, the campus in general). Here we are going to discuss the importance of university extension in training/continued training of Geography teachers and students in the current social and economic context of neo-liberalism.
\end{abstract}

Key words: Geography teaching, university extension, public school.

\title{
APRESENTAÇÃO
}

Existe uma grande separação entre o que é produzido e estudado nos cursos de nível superior de geografia e o que se ensina/produz/reproduz no cotidiano das escolas públicas de ensino básico na disciplina de geografia. Essa é uma afirmação reiterada pelos alunos que optam ${ }^{2}$ fazer a Licenciatura em Geografia.

Frente a essa constatação que fazer? Como articular o que está sendo produzido academicamente, que é debatido e ensinado nos cursos superiores, com a realidade escolar encontrada nas escolas, de modo que a geografia ajude a entender os atuais processos de produção do espaço e suas implicações na vida cotidiana? Não se trata de reproduzir as discussões travadas na universidade, mas como pensar esse debate na realidade e possibilidade de compreensão dos alunos da escola básica (fundamental e médio).

Tentando apresentar possibilidades de superar a questão posta que alunos do curso de geografia em 2002 elaboraram um projeto de extensão universitária denominado "Semana de Geografia" que se desenvolve até o momento e do qual faremos uma avaliação, tomando como foco a formação de professores e alunos.

A Semana de Geografia se realiza todos os anos desde 2003 com atividades nos dois semestres letivos: os grupos de estudos se reúnem uma vez ao mês para debater textos/livros sobre ensino e ensino de geografia; em outubro há a vinda das escolas com a apresentação dos projetos realizados em escolas públicas, bem como mesas de debates e minicursos de temas do ensino de Geografia para professores e interessados.

2 O curso de Geografia da Universidade de São Paulo - Brasil forma geógrafos (bacharéis). Estes têm a opção, desde o primeiro ano de curso, de concomitantemente também fazer a licenciatura em Geografia. 
Apresentadas as atividades realizadas na Semana de Geografia, procuraremos avaliar o impacto e as consequências desse projeto de extensão a partir da análise dos sujeitos participantes desse processo em cada uma das atividades realizadas e dos espaços instituídos, lembrando de que eles se articulam como um todo, só podendo ser entendido o processo a partir dessa articulação.

Temos nesse processo a Universidade, onde se produz e se deveria difundir o conhecimento e a Escola pública que deveria promover o ensino de forma a permitir a construção de cidadãos críticos e potentes na sociedade. Nessas duas instituições, que se espacializam, temos os sujeitos que analisaremos nesse processo: professor e aluno.

Antes de iniciar a análise devemos deixar claro o que entendemos por extensão universitária: processo de troca entre o produzido na Universidade e, no caso de nossa análise, o que é produzido na Escola. Não entendemos a extensão, como durante muito tempo foi realizada e sobre a qual Paulo Freire (1987) fez duras críticas, que se trata de um processo em que um sujeito que "oferece" conhecimento e outro que o "incorpora, aceita" . Usamos as aspas, pois, na visão do autor, tratavase, naquele contexto dos anos 70 na América Latina, de uma forma de invasão cultural, buscando, a partir da difusão e incorporação de determinados conhecimentos à dominação.

Embora não estejamos mais no contexto das ditaduras de direita na América Latina, o projeto de dominação e domesticação, necessários ao desenvolvimento do capital continua existindo, mas sob novas formas. Como nos mostra Soares (2011), os PCNs (Parâmetros Curriculares Nacionais) ${ }^{3}$ são a resposta, a nível educacional, que coaduna com o novo paradigma produtivo pautado nas políticas neoliberais, de Estado mínimo, difundido a partir do Consenso de Washington ${ }^{4}$ e na Educação um ano mais tarde com a "Declaração de Jomtien"

Em nossa análise, e já nesse novo contexto mundial, a proposição de extensão feita pelos alunos, em 2002, buscava resistir à lógica de formação domesticada para o mundo do trabalho, que se reforça a partir de $2008^{6}$ principalmente no Estado de São Paulo e, ao mesmo tempo, conseguir esse intento a partir da possibilidade de real troca de conhecimentos entre o produzido na Universidade e o na Escola, e mais do que isso, criação de novos conhecimentos possibilitados por essa relação.

Nesse sentido a I Semana de Geografia foi proposta com esse objetivo. Ela, até hoje, tem seu

3 Nos anos 90 são lançados no Brasil os PCNs (BRASIL, 1996) que deveriam orientar a formulação dos currículos em todo país.

4 O consenso de Washington aponta um receituário a ser seguido pelos governos dos Estados latino americanos e africanos principalmente. Um de seus maiores impactos foi a desregulamentação no mundo do trabalho que implicou na necessidade de uma nova formação do trabalhador, interferindo diretamente no ensino. Agora o novo trabalhador, e a nova educação para isso, deveriam privilegiar a formação de habilidades e competências, bem como a eficiência, entendida nesse contexto como uma aprendizagem em rápida e com menor custo.

5 Documento elaborado em 1990, durante a Conferência Mundial de educação para todos, realizada na Tailândia.

6 Em 2008 é lançado no Estado de São Paulo (Brasil) a Proposta Curricular do Estado de São Paulo(SÃO PAULO, 2008) que em 2011 deixa de ser oficialmente propostas e é transformada em Currículo do Estado de São Paulo. A análise aprofundada das implicações desse currículo pode ser acessada em PEREIRA (2011). A partir de 2008 o Estado de São Paulo passa a produzir os materiais didáticos para todas as disciplinas, tendo como fundamento a possibilidade do aluno ingressar no mundo do trabalho a partir do desenvolvimento de competências e habilidades durante sua formação escolar. 
processo de realização durante todo o ano, sendo que no primeiro semestre, são feitos convites ${ }^{7}$ aos professores da rede pública da região metropolitana de São Paulo para desenvolverem projetos de geografia, interdisciplinares ou não, que são acompanhados, ou têm o apoio logístico, dos alunos que estão cursando a Geografia na USP. Ainda que não seja oficialmente um estágio supervisionado (embora desde 20088 pode ser considerado caso o aluno pleiteie) o aluno acompanha a realização do mesmo na escola, debate com os professores responsáveis pelo projeto, auxilia nas dúvidas dos alunos do ensino básico que fazem parte do projeto, bem como é responsável pela condução dos alunos dessa escola ao Departamento de Geografia da USP, onde mostram e discutem os resultados do projeto às outras escolas aos alunos/professores do curso de Geografia e demais interessados no debate.

Além disso, eles também são responsáveis por apresentar aos alunos das escolas participantes a USP. Há um roteiro monitorado e discutido entre os membros da Semana que inclui visita a outras unidades didáticas, museus, bandejão (Restaurante Universitário) e demais espaços, incluindo de lazer, na universidade. Esse conjunto de atividades realizadas pelos alunos que estão sendo formados para ser professores é denominado, no Projeto Semana de Geografia, de Escola de Projetos.

\section{ESCOLA DE PROJETOS}

Ao longo de uma década pudemos ter uma ideia do que representa a Escola de projetos para as escolas que dela participam bem como para os alunos que delas são monitores a partir das avaliações ${ }^{9}$ que se realizam após o término de cada Semana e pelas entrevistas e depoimentos dos professores e alunos participantes.

Para alguns professores o realizar um projeto de geografia na escola pública, teve como incentivo a possibilidade de ir a USP e lá apresentá-lo. Para esses foi um pontapé inicial, pois após da experiência continuaram a realizar projetos na escola, mesmo que não tivessem mais o propósito de vir a USP. Outros mantiveram essa perspectiva (de apresentar o trabalho realizado durante a Semana de Geografia), segundo eles, para conseguirem apoio e autorização da direção da Escola para realizá-lo. Segundo relatos dos professores, muitas direções de escola só permitiam que esses projetos fossem realizados na escola com essa perspectiva (apresentação na USP) e, em algumas, apenas podiam realizá-lo nos horários extra classe ${ }^{10}$ e de forma voluntária aos alunos.

$7 \quad$ Entre janeiro e fevereiro de cada ano é enviada a todas as escolas da rede pública de ensino da Região Metropolitana de São Paulo uma carta que explica o que é a Semana de Geografia e convida os professores de Geografia a enviarem projetos que serão desenvolvidos nas escolas para, posteriormente, os alunos dessas escolas poderem apresentá-los na Universidade e também conhecê-la.

8 Em 2006 a USP lança o Programa de Formação de Professores da USP que promover maior integração entre as Unidades para a formação dos licenciados da USP, buscando ter "na formação de professores e no compromisso com a melhoria do ensino público uma preocupação constante e uma ação integrada e renovadora"(USP, 2004).

9 Ao final de cada Semana é elaborado um relatório final que é apresentado e avaliado pelo Departamento de Geografia da FFLCH-USP, Pró-reitoria de Graduação e Pró Reitoria de cultura e extensão.

10 Nas escolas públicas do Estado de São Paulo, o uso do Material criado pelo Estado de São Paulo (caderno do aluno e caderno do professor) acaba por se tornar uma camisa de força já que os professores não podem fazer nada que não esteja programado nesse material. Quando o professor resolver realizar um projeto, em algumas escolas ele é questionado como vai dar conta do projeto e do material do Estado, que nessa ótica, é o prioritário. 
Já outros professores realizam projetos em suas escolas como uma prática rotineira e, apresentar na USP era uma forma de dar visibilidade ao trabalho feito junto com os alunos, mas que muitas vezes não fica registrado e se perde ao longo do tempo.

Tanto em um como noutro caso temos, dentre os projetos selecionados e que são acompanhados durante o ano, um ou dois de escolas que já participaram da Semana de Geografia em algum dos anos anteriores. Além disso, no contato que temos com os professores muitos afirmam que passaram a ser cobrados para que haja projetos que, segundo os alunos, quebram a monotonia (quando o professor se restringe ao uso de livros didáticos ou dos cadernos do Estado de SP) do trabalho realizado em sala.

Para os alunos, também a partir dos relatos, a realização de Projetos de Geografia, muitas vezes feitos de forma interdisciplinar, permite ter maior contato com a realidade. Eles passam a ver o problema real, fazendo com que o que se aprende em geografia tenha maior significado. Na VIII Semana de Geografia (2011) tivemos um relato, durante os debates realizados no anfiteatro de Geografia, de uma aluna de 12 anos de idade que dizia que após trabalho de campo ${ }^{11}$ realizado na aldeia guarani Tekoa Pyau existente no Pico do Jaraguá (SP), conseguiu perceber que, mesmo morando na periferia, sem acesso a muitas coisas que existem em outras partes da cidade há lugares/situações muito piores, como o que ela presenciou na aldeia e, ao mesmo tempo, outras situações de luta pela terra $^{12}$. No final do debate afirmava que graças ao projeto realizado na escola entendia que muitos vivem em situação precária por não terem acesso a terra e que agora lutava pela Reforma Agrária e pelos movimentos sociais. Para ela a realização do projeto, que incluía trabalhos de campo e cujos conceitos trabalhados foram diferenciação socioespacial, exclusão socia $1^{13}$ e periferia, foi um marco em sua aprendizagem e que esperava que outros projetos ocorressem na escola.

Embora hoje na Geografia haja o debate sobre o conceito de periferia, se ainda poder-se falar da relação centro- periferia para explicar a atual produção do espaço, para os alunos dessa escola, a periferia se revela no cotidiano em seu conceito clássico, isto é o trabalhado na Geografia dos anos 70 até os 90 (sec. XX), ou seja entendida como

...porções de qualquer aglomeração urbana, localizadas via de regra na porção próxima aos limites externos da área edificada, onde predomina a ocupação residencial pelas camadas mais pobres da população, estabelecida ali de modo bastante precário. (Langenbuch, ,2001, p. 89)

Para esses alunos a periferia onde moravam é a marcada pelas carências - de agências bancárias, internet, áreas de lazer e cultura, com dificuldades no transporte. Para eles os lugares que reconheciam como locais onde podiam suprir algumas das necessidades não encontradas no bairro, ou seja centralidades, mesmo que não tenham usado essa terminologia, estavam na Lapa, em Pirituba,

$11 \mathrm{Na}$ apresentação do projeto "As transformações tecnológicas e as diferenciações socioespaciais nas diversas escalas geográficas" a escola exibiu um vídeo sobre a sua realização. Ele pode ser encontrado no youtube, em duas partes: primeira parte em http://www.youtube.com/watch? $=c 5 u 3 j p k$ pg0\&feature=youtu.be e a segunda parte em http://www.youtube.com/watch?v=zqWaxAAcgC0\&feature=youtu.be

12 No projeto houve ainda uma visita a Comuna da Terra Irmã Alberta, do MST (Movimento dos sem terra). Tanto a Aldeia indígena como a comuna ficam próximas a Escola Municipal Marili Dias, onde se realizou o projeto.

13 Sobre debate entre o uso do conceito de segregação e exclusão social ver ALVES(2013). 
centralidades tradicionais da cidade, e não no local que viviam - o Morro Doce. A Escola de Projetos é uma tentativa de incentivar o desenvolvimento pelos professores de projetos que levem o aluno a analisar criticamente a realidade a partir de experiências propostas pelos professores. Muitos, ao longo desses anos de realização da Semana, se valeram de proposições que utilizavam o trabalho de campo como uma metodologia. Outros desenvolviam projetos a partir de realização de pesquisas em grupo, cujos resultados deveriam ser apresentados a partir de diversas linguagens como: elaboração de mapa coletivo de fluxos migratórios a partir de entrevistas realizadas pelos alunos, criação de música sobre a temática trabalhada, peças de teatro, elaboração de maquetes, apresentações em PowerPoint, criação de vídeos, entre outros.

Foi recorrente na proposição e realização do trabalho, embora não tenha sido exclusivo, o uso do lugar como ponto inicial para o desenvolvimento do projeto. A categoria lugar ganha assim importância no desenvolvimento de pesquisas escolares de Geografia. Trabalhos que partiam do conhecimento do lugar, a partir da pesquisa de sua produção e transformação ao longo dos anos permitiam aos alunos começar a pensar em processo histórico. Como nos fala (Massey, 2000, p.184) o lugar é um processo e entendê-lo pressupõe ter "consciência de suas ligações com o mundo mais amplo" . Em alguns trabalhos ${ }^{14}$ os alunos se surpreendem descobrindo que o córrego que hoje é esgoto a céu aberto um dia foi local de lazer para seus pais e tios. Que espaços em que hoje predomina o cinza dos blocos de cimento, no passado era uma área de chácaras.

Queremos enfatizar que embora vejamos potencialidades na elaboração e desenvolvimento de projetos nas escolas, isso não deve ser institucionalizado enquanto norma ou obrigatoriedade, pois, a nosso ver, imobilizaria o professor, que faria o projeto por exigência e não porque acha que pode ser uma estratégia a mais para envolver e desenvolver o senso crítico dos alunos. Boscolo (2007) faz um alerta a esse tipo de situação. Em sua pesquisa analisa o desenvolvimento de projetos em uma escola da região metropolitana de São Paulo mostrando sua potência. Mas quando a Secretaria de educação desse município estudado passa a exigir que todas as escolas, obrigatoriamente, tenham que desenvolver um determinado tipo de projeto (predeterminado pela Secretaria municipal de educação) na escola, o que antes era feito por iniciativa de grupos de professores que buscavam um compartilhar projetos de escola, ou seja, construir juntos o projeto político pedagógico não como formalidade mas como potencialidade, quando passa a ser obrigatório em toda as escolas perde sua potência e passa a ser realizado como forma de "check list". Deste modo todas as escolas tinham um projeto, mas sua realização era, muitas vezes, burocrática.

A ida das escolas à Universidade por sua vez, permitiu que muitos alunos desmistificassem a ideia que dela faziam. A USP aparece para os alunos das periferias onde se localizam as escolas participantes, como um lugar da elite ${ }^{15}$ e da qual não tinham a mínima chance de fazer parte. Conhecer os espaços, ver os alunos dos cursos da USP presentes em algumas unidades didáticas como nos prédios da FFLCH (Faculdade de Filosofia, Letras e Ciências Humanas), comer no bandejão

14 Na III Semana de Geografia (2006) alunos da Escola Estadual São Paulo, localizada no centro da cidade de São Paulo, mas que moram nas periferias da cidade, deram o depoimento da descoberta, a partir das entrevistas com antigo moradores, de que a história não começa com eles na atualidade, que se trata de um processo.

15 No Brasil a maior parte dos alunos de famílias de baixa renda estuda em escolas públicas, enquanto que os de maior poder aquisitivo em escolas privadas durante o ensino básico (fundamental e médio). No nível superior essa equação se inverte: os alunos de baixa tenda acabam, quando podem, cursando seu bacharelado e/ou licenciatura em faculdades/centros universitários e ou universidades privadas enquanto que os alunos de famílias de bom poder aquisitivo estudam nas melhores Universidades públicas do país. 
(restaurante central), passear pela Praça do Relógio, visitar o MAC (Museu de Arte Contemporânea), bem como outros museus existentes na USP, associado a informações sobre novos programas de inserção dos alunos na Universidade ${ }^{16}$, permitiu que vários desses alunos pensassem na possibilidade de cursá-la, o que para alguns tornou-se realidade. Esse conhecimento dado pela vivência, pela relação corpórea, a possibilidade do contato, da troca, do reconhecimento ou estranhamento frente a uma dada situação, é a expressão direta da vida urbana que, segundo Lefebvre (2010: 22),

...pressupõe encontros, confrontos de diferenças, conhecimentos e reconhecimentos recíprocos (inclusive no confronto ideológico e político) dos modos de viver, dos "padrões" que coexistem na Cidade.

Em nossa contemporaneidade o que temos parece ser justamente o oposto, a negação da vida urbana, a partir da separação socioespacial que pode chegar a segregação socioespacial, com a negação do outro a partir da criação de consensos. A escola pública tem problemas sim, mas dizer que a saída para a educação é a partir da privatização da mesma é um desses consensos que estão sendo gestados. Mostrar que na escola pública também aparecem alternativas, possibilidades, é uma das proposições da Semana de Geografia, de forma que tenham visibilidade, não como exceções mas como fato recorrente, de forma que haja a realização da educação para a formação do cidadão crítico e potente em nossa sociedade.

Enfatizamos que não se trata da Universidade levar conhecimentos à Escola e esta os incorporar. Falamos de troca de conhecimentos e experiências, de forma a que extensão seja a possibilidade da criação, pela troca, de novos conhecimentos.

Tratamos aqui que conhecimento no sentido lato da palavra. Nessa troca foi surpreendente descobrir que vários dos monitores da Semana passaram a conhecer alguns dos espaços e serviços da universidade a partir dessas visitas por eles próprios monitoradas. Nas avaliações ao final de cada Semana, vários monitores falavam relatavam a visita das escolas e com deslumbre diziam ter conhecido, junto com os alunos das escolas públicas, o Museu da Geologia, da Oceanografia, o Paço das artes, o Instituto Butantã ${ }^{17}$, entre outros espaços até então também desconhecidos para eles.

Para os monitores, esse projeto de extensão possibilitou rever a relação Universidade- Escola pública. A maior parte deles são alunos egressos da escola pública. Por vezes se perguntavam se era isso mesmo que queriam, já que em sala de aula sempre se questionavam porque da distância entre o que se ensina no curso e o que se aprende na escola pública. A partir do desenvolvimento dos projetos percebem que é possível sim aproximar essas duas dimensões, tomando como ponto de partida situações concretas analisadas nos projetos.

Além disso, a maior parte dos monitores faz parte dos programas de inclusão citados na nota anterior. Segundo alguns deles, não fossem esses auxílios, mesmo a USP sendo gratuita e pública, eles não teriam como se manter na Universidade. Mas foi a associação entre projetos de inclusão e

16 PASUSP, INCLUSP, além da existência das bolsas para permanência na Universidade ( Ensinar com pesquisa, Aprender com extensão, PEEG) bem como os auxílios (moradia, alimentação, livros, transporte, por exemplo) e as possibilidades de uso do Hospital Universitário e outros serviços na Coseas. O detalhamento de todos esses programas se encontra no site: www.usp.br

17 Embora não faça parte da USP, o Instituto Butantã é um centro de pesquisas e ao lado da USP. 
projetos de extensão que permitiu a muitos deles se encontrar no curso, decidir-se por fazer a licenciatura e tentar mudar a realidade por eles encontrada e vivida.

\section{OS GRUPOS DE ESTUDO}

Os grupos de estudo tiveram maior regularidade (uma vez ao mês durante todo o ano) a partir de 2008. Esse momento de análise de textos/livros é aberto a todos que estejam interessados na discussão sobre o ensino e o ensino de Geografia. Entretanto predomina a participação dos monitores bolsistas, seguidos de alunos não bolsistas do curso de bacharelado/licenciatura em Geografia e, em número bem mais restrito, de professores da rede pública.

O grupo de estudos tem se mostrado uma ação a mais no processo de formação de professores de geografia ao longo da realização do curso de bacharelado/licenciatura. Os textos são selecionados no início de cada Semana e, em geral, estão alinhados com a proposta temática da Semana.

Apenas para exemplificar: em 2011 realizou-se a VIII Semana de Geografia "Geografia do Trabalho e as transformações no/do mundo contemporâneo". Fazia parte do rol de textos a ser debatidos o livro de Resende (1986), de Mészaros (2005), Harvey (1994) entre outros, que propiciaram discussões, se tomarmos o conjunto como um todo, sobre a questão educação/ensino/mundo do trabalho/geografia.

No momento do grupo de estudos foi possível articular conhecimentos que são fragmentados no curso de formação com as problemáticas vivenciadas nas escolas públicas. O trabalho, no seu sentido mais amplo de nossa realidade, faz parte da vida cotidiana dos alunos: desde aqueles que estão desempregados ou buscam trabalho, aos que têm carteira registrada e os que trabalham na precariedade, fazendo "bicos" 18 .

Nessa Semana todas as apresentações das escolas seguiram essa temática: trabalho, migração, consumo, transformação do lugar. Alguns trabalhos merecem destaque, pois foi nítido o quanto os processos históricos, principalmente ao nível cotidiano, ficam obscurecidos quase apagados. Um dos projetos enfatizava a pesquisa por meio de entrevistas a familiares e conhecidos sobre a história de vida, migração e trabalho. Os alunos na apresentação, feita a partir da exibição de um vídeo, destacaram a importância do trabalho, pois puderam conhecer a história de sua família, os motivos que levaram a migrar, o porquê os pais irem morar nas regiões periféricas onde vivem, quais as transformações que ao longo de três ou quatro décadas o lugar sofre, enfim afirmaram só agora ter dimensão da importância e da luta a partir do trabalho de seus familiares. Foi a partir do projeto de Geografia que passaram a perceber que os fatos não começam agora, eles fazem parte de um processo que precisa ser conhecido para que possa ser transformado.

\section{AS MESAS DE DEBATES E OS MINI CURSOS}

Embora a nosso ver, a atividade Escola de projetos seja o ponto alto da Semana, a participação do alunos do curso de graduação não é alta (exceção ao alunos bolsitas e não bolsistas que par-

18 Fazer bicos em português significa fazer o que for possível por algum trocado, em geral sem registro, pro um período determinado de tempo que pode ser até mesmo de um dia. 
ticipam de todas as atividades da Semana), ou seja, parece não haver muito interesse em saber o que se produz na Escola pública. A atividade de extensão ainda envolve poucos no universo mais geral de docentes e alunos. Deste modo o famoso tripé da Universidade- ensino, pesq uisa e extensão- existe a partir de uma hierarquia - pesquisa, ensino e extensão, mas como esse não é nosso foco não nos debruçaremos sobre essa questão embora seja necessário apontá-la.

Apesar disso uma das atividades da Semana tem maior participação do conjunto de alunos da graduação: trata-se das mesas de debates. Elas ocorrem durante a Semana de Geografia no período noturno e para sua realização são convidados pesquisadores da temática proposta para cada Semana e profissionais que trabalham com a mesma. Isso demonstra uma preocupação com a formação teórica, mas que, a nosso ver, tende a dissociar a teoria e prática, ou seja , não atinge a práxis. Segundo LEFEBVRE (2010:102)

Apenas uma práxis, em condições a serem determinadas, pode se encarregar da possibilidade e da exigência de uma síntese, da orientação na direção desse objetivo: a reunião daquilo que se acha disperso, dissociado, separado, e isso sob a forma da simultaneidade e dos encontros.

Já que enfatizamos o tema trabalho e continuando a partir dele, tivemos uma mesa da VIII Semana que discutia a crise do mundo do trabalho. Durante os debates foi questionado aos palestrantes como levar essa discussão para o ensino médio, ao que um constrangedor silêncio se fez. Harvey, Kurz, autores citados na palestra, pareciam ficar fadados a ter seu pensamento discutido apenas na academia. Frente a esse incômodo científico, na plateia um participante declara: "essa questão foi respondida à tarde por um grupo de alunos do ensino médio, mas poucos parecem querer saber o que eles pensam".

Ainda existe um grande preconceito contra os saberes escolares e, no caso da geografia, contra a geografia escolar ${ }^{19}$. Ao contrário do que se afirma, há sim por parte de muitos professores a busca pela construção do conhecimento, pela atualização constante. Em todas as Semanas de Geografia há o espaço para a realização de mini cursos, cujos ministrantes envolvem um leque grande e variado de profissionais. Temos docentes da Universidade, alunos de pós graduação, alunos do bacharelado/licenciatura, professores da rede, todos preocupados em discutir com os pares novos conhecimentos, novas metodologias e técnicas. Nessa Semana cujo tema era o mundo do trabalho, nas apresentações o que vimos foram alunos falando de fordismo, toyotismo, acumulação flexível e citando autores como Milton Santos, Harvey entre outros, o que mostra que o debate acadêmico, principalmente aquele que envolve/atinge o cotidiano se faz presente.

Nesse projeto de extensão que é a Semana de Geografia temos tido a experiência da troca, do debate, do aprender, criando a partir desse processo. As mudanças ainda aparecem como potencialidades, e ocorrem na escala do cotidiano escolar de determinadas escola, mas já é um começo para mudanças que podem iniciar-se na escala do lugar e, em um projeto de construção de um mundo mais justo, menos desigual e mais solidário, saltar escalas e, quem sabe, chegar ao global.

19 Segundo Cavalcanti (2008: 28) “... a geografia escolar é o conhecimento geográfico efetivamente ensinado, efetivamente veiculado, trabalhado em sala de aula." 


\section{REFERENCIAS}

Alves, G. Da A. Abordagem da segregação socioespacial no ensino básico de Geografia in Vasconcelos, P. De A. ; Corrêa, R. L. ; Pintaudi, S. M. (Orgs.). A cidade contemporânea, segregação espacial, São Paulo: Contexto, 2013, pp. 189-202.

O lugar como possibilidade de conhecimento da realidade escolar in IX Colóquio internacional de Geocrítica. Disponível em: http://www.ub.edu/geocrit/9porto/gaalves.htm

Brasil. Parâmetros curriculares nacionais, ensino fundamental II. Secretaria de Educação Fundamental. . Brasília : MEC, 1998 disponível http://portal.mec.gov.br/seb/arquivos/pdf/geografia.pdf

Boscolo, D. Projetos de estudo do meio em escolas públicas em Santana do Parnaíba, São Paulo: FFLCHUSP, 2007 (dissertação de mestrado). Disponível em http://www.teses.usp.br/teses/disponiveis/8/8136/tde-18102007-154606/pt-br.php

Cavalcanti, L. de S. A geografia escolar e a cidade. Campinas: Papirus, 2008.

Freire, P. Pedagogia do Oprimido, 17 ed. Rio de Janeiro: Paz e terra, 1987. Disponível em http:// portal.mda.gov.br/portal/saf/arquivos/view/ater/livros/Pedagogia do Oprimido.pdf

Harvey, D. Condição Pós-moderna, São Paulo: Loyola, 1996.

Langenbuch, J. R. .Depoimento. Espaço \& Debates, 42, São Paulo: NERU, 2001, pp.85-91.

Lefebvre, H. O direito à cidade,5 ed. São Paulo : Centauro, 2010.

Massey, D. Um sentido global do lugar. in ARANTES, Antonio A . (Org) O espaço da diferença. Campinas: Papirus, 2000, pp.176-185.

Mészáros, I. A educação para além do capital. Tradução de Isa Tavares. São Paulo: Boitempo, 2005. $77 \mathrm{p}$.

Morais, E.M.B de. e Moraes, L.B. de. Formação de professores: conteúdos e metodologias no ensino de Geografia, Goiânia: NEPEG, 2010.

Pereira, S. de C. A proposta Curricular do estado de São Paulo e a sala de aula como espaço de transformação social, São Paulo: FFLCH-USP, 2011 (tese de doutorado). Disponível em http://www.teses. usp.br/teses/disponiveis/8/8136/tde-24102012-123823/pt-br.php

Resende, M. S. A geografia do aluno trabalhador caminhos para uma prática de ensino. São Paulo, Loyola, 1986.

Santos, M. O intelectual e a Universidade estagnada, Revista Adusp, São Paulo : Adusp, out, 1997.

Santos, M. O espaço do cidadão. São Paulo: Nobel, 1987. 
São Paulo (Estado). Proposta curricular do Estado de São Paulo - São Paulo: Secretaria da Educação do Estado de São Paulo, 2008.

Soares, M. de O. O novo paradigma produtivo e os parâmetros curriculares nacionais de Geografia. São Paulo : FFLCH-USP, 2011 (tese de doutorado) . Disponível em http://www.teses.usp.br/teses/ disponiveis/8/8136/tde-17082012-102430/pt-br.php

USP. Programa de Formação de Professores da USP, São Paulo: Pró- Reitoria de Graduação: 2004. Disponível em http://www.prg.usp.br/site/images/stories/arquivos/pfp.pdf

Vídeo

E.M.Marilia Dias- http://www.youtube.com/watch?v=c5u3jpk pg0\&feature=youtu.be

e http://www.youtube.com/watch?v=zqWaxAAcgC0\&feature=youtu.be

$\underline{\text { Sites }}$

www.usp.br

Articulo recibido en abril 5 de 2013 - Aprobado en mayo 15 de 2013 